\title{
COMPLICATIONS OF CLOSED CHEST CARDIAC COMPRESSION
}

\author{
M. MinuCK, M.D.*
}

A MOMENTOUS ADVANCE in the management of cardiac arrest was made in 1960 when Kouwenhoven, Jude, and Knickerbocker ${ }^{1}$ demonstrated that indirect cardiac compression through intermittent sternal pressure could produce an effective pulmonary and systemic circulation. An efficient circulation can be maintained even when the arrest is due to ventricular fibrillation. ${ }^{1,2}$

By placing water-filled balloons inside the pericardium of cadavers from which the heart had been removed and by measuring brachial artery pressintes, Pryor demonstrated that adequate peripheral "pressures could be obtained by sternal compression. ${ }^{3}$ These pressures were as high as those produced by direct cardiac compression. Redding and Cozine ${ }^{4}$ demonstrated the same comparison in dogs. When this technique is combined with effective artificial ventilation, a patient may be kept "alive" until the type of arrest is diagnosed, and specific treatment instituted. ${ }^{5}$ Particularly worthy of note is the fact that a number of patients whose hearts stopped following a myocardial infarction have been successfully resuscitated. 6,7 The usefulness of closed chest cardiac compression has been substantiated by the many reports of successes from countries throughout the world. No fewer than fifty articles about this technique have been published in the six months reviewed by the author. ${ }^{8}$

In recent months there has been an increase in the number of reports of serious complications that are the direct result of the vigorous force required to move the sternum posteriorly in order to produce an adequate compression of the ventricles. The most frequent injuries reported are fractures of the ribs and sternum. ${ }^{9,10}$ These injuries to the bony thorax range from simple fractures of one or two ribs to a completely "stove-in" chest. ${ }^{11}$

Baringer et al. ${ }^{9}$ and Clark ${ }^{10}$ reviewed the complications following closed chest cardiac massage in 84 and 18 cases respectively and mentioned instances of damage to the bony thorax, to the pericardium, myocardium, kidney, spleen, aorta, large veins, and liver.

In the July 16, 1961, issue of the New England Journal of Medicine Morgan ${ }^{12}$ reported what he thought was the first case of hepatic laceration following closed chest cardiac compression. Baringer's ${ }^{9}$ report appears in the same issue and describes five instances of liver injuries of varying degrees of severity. Clark's ${ }^{10}$ review in July 1962 also contains four cases of minor liver damage. In none of his cases did the bleeding from the liver exceed 300 c.c. On the other hand, Thaler and Krausise $\mathrm{e}^{13}$ in September, 1962, presented two cases of severe lacerations to the liver in children following external cardiac compression.

${ }^{*}$ Director, Department of Anaesthesia, St. Boniface General Hospital, St. Boniface, Manitoba; Assistant Professor, Department of Surgery, Anaesthesia), University of Manitoba, Winnipeg, Manitoba. 


\section{Case Report}

Mrs. D P

Chart No. 62-18754

This 65-year-old female was admitted to hospital on October 20, 1962. Radiological investigation revealed the presence of a large space-cccupying lesion placed deeply above the right lateral ventricle in the parieto-occipital region. History, physical, and laboratory findings were normal, except for signs referable to her surgical condition and for the presence of a funnel chest. On October 25, 1962, she came to the operating room for a craniotomy. She was induced with thiopentone and succinylcholine, and intubated and maintained on oxygen and nitrous oxide and halothane. Profuse bleeding was encountered after the bone flap was raised and, in spite of three rapid transfusions of blood and dextran through two and three veins, within minutes pulse, blood pressure, and respirations ceased and the pupils became dilated and fixed. Closed chest cardiac compression was started and after one minute, $1 \mathrm{gm}$. of calcium chloride was injected into the ventricle. This was followed by 2 c.c. of epinephrine, 1 in 10,000. The administration of blood and dextran 6 per cent was continued, along with closed chest cardiac compression. After 20 minutes, ventricular flutter was seen on the cardioscope. Procaine amide $100 \mathrm{mg}$. was injected and an infusion of $8 \mathrm{mg}$. of norepinephrine in $1000 \mathrm{c.c}$. of 5 per cent glucose in water was started. Within one minute, the rhythm reverted to normal and for the first time a blood pressure was obtained (110/70). The patient awoke and required further anaesthesia for the completion of the operative procedure. The tumour (an astrocytoma) was biopsied and the wound closed. Although no further bleeding was encountered, the patient's condition began to deteriorate again and she died one hour after the completion of the operation.

The most striking finding at post mortem was the presence of more than 3,000 c.c. of blood in the peritoneal cavity, which resulted from a severe liver laceration (see Fig. 1). The sternum, which was fractured at the angle of Louis, pre-

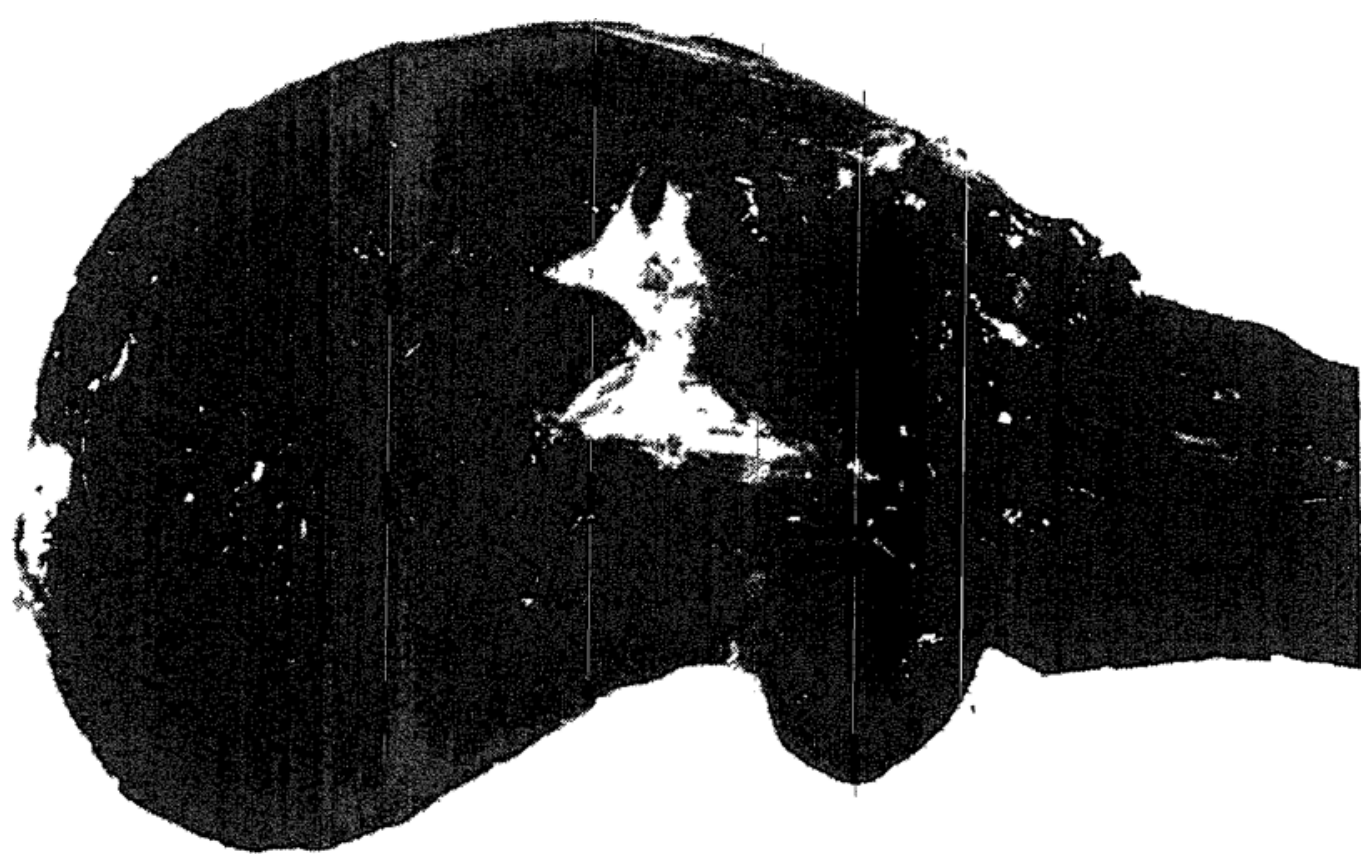

Figure 1. A coronal section has been made through the liver. The lower edge of the laceration is indicated by the arrow, and it extends through the liver to its upper marg.n. A large haematoma can be seen surrounding the tear 


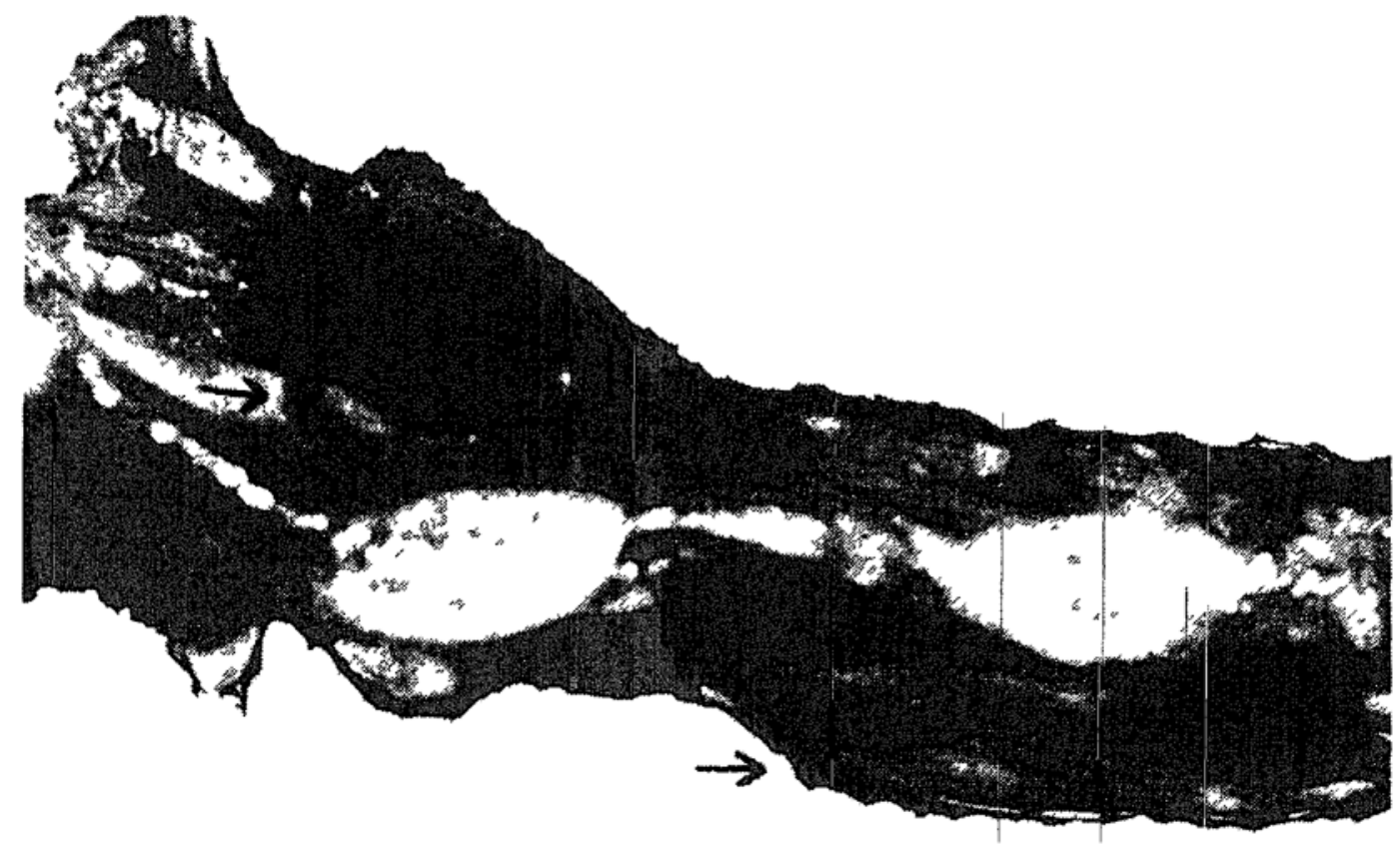

FIGURE 2. The arrow to the left points to the fracture through the sternum The arrow to the right points to the protuberance of bone which projected from the dorsal surface of the stemum. The xuphisternum, which extends to the nght of the photograph, unfortunately has been omitted.

sented a large knob of bone on its inner aspect at the lower| end, related to the pectus excavatum. This protuberance overlaid the liver and undoubtedly contributed to the serious liver laceration (see Fig. 2).

\section{Comment}

This case is being reported primarily because of the interesting feature presented by the funnel chest (see Fig. 1). The depression caused by this congenital anomaly acted as a battering ram, so that with each forceful depression of the sternum the knob of bone would compress the liver against the vertebral bodies, causing the eventual laceration. In' spite of this, after 20 minutes of almost continuous closed chest cardiac compression, the patient recovered from the arrest. The level of consciousnes was such that nitrous oxide and halothane had to be added to the oxygen to enable the surgeon to complete his procedure. The patient deteriorated rapidly and progressively towards the end of the procedure and in the immediate postoperative period, in spite of more transfusions, and she finally died.

\section{Discussion}

During the past two years at our hospital, a large number of people whose hearts have stopped have been subjected to closed chest cardiac compression. In these cases our philosophy has been "treat first, ask questions later." The sequence is: (1) to establish an airway, (2) to maintain ventilation, (3) to perform closed chest cardiac compression, (4) to determine the details of the death. The decision 
for continuing is based on these details and has been discussed by the author in a previous publication. ${ }^{5}$

Our survival rate is extremely low, owing to the presence of severe disease, but we have been encouraged by our few successes in patients whose survival seemed impossible. It is true that many of the patients, including the survivors, sustained some fractured ribs, and possibly some minor haemorrhages into the myocardium, and one instance of a severely lacerated liver occurred. Our complications were due to lack of experience, haste, and unduly severe sternal compression.

In spite of the potential complications which may follow closed chest cardiac compression (thoracotomy can also have untoward results, such as incised lungs, transected internal mammary arteries, ruptured ventricles and atria), I suggest that this technique, combined with artificial ventilation, is the ideal method of treatment for the patient whose heart stops outside the hospital. In the hospital, it is the method of choice except under the following conditions:

1. When the patient has a "stove-in" chest.

2. When the patient has a funnel chest.

3. When one suspects the possibility of $(a)$ air embolism, $(b)$ cardiac tamponade, or $(c)$ bilateral pneumothorax.

4. When ventricular fibrillation exists and no external defibrillator is available.

5. When it is not possible to identify the type of arrest

6. If a patient has a cardiac arrest in the operating room and there is no adequate response after 2 minutes of closed chest cardiac compression.

7. If it is known that the patient has a severe degree of mitral stenosis, then thoracotomy and finger commissurotomy should be done prior to the institution of direct cardiac compression. ${ }^{14}$

In these situations thoracotomy will facilitate diagnosis, viz., of tamponade, ventricular fibrillation, etc., and treatment.

\section{SUMMARY}

The author has reviewed the complications of closed chest cardiac compression that have been reported in the literature. These include rib fractures, sternal fractures, haemorrhages into the pericardium, epicardium, and myocardium. Trauma to the great vessels, spleen, and liver has also been reported. A case of massive intraperitoneal bleeding from a lacerated liver that followed "successful" treatment of cardiac arrest by means of closed chest cardiac compression is presented. The patient had a funnel chest, which resulted in a projection of bone being present in the inner aspect of the lower end of the sternum, and it was felt that this contributed to the severe trauma to the liver. Finally, the author lists a number of situations when the physician should treat cardiac arrest by direct cardiac compression rather than by closed chest cardiac compression.

\section{RÉSUMÉ}

L'auteur a passé en revue les complications de la compression cardiaque en thorax fermé, complications dont il est fait mention dans la littérature. On rap- 
porte des fractures dé côtes, des fractures de sternum, des hémorragies intrapéricardiques, épicardiques et myocardiques. On a également signalé des traumatismes aux gros vaisseaux, à la rate et au foie. Nous présentons un cas d'hémorragie intrapéritonéale massive due à des lacérations du foie à la suite du traitement "efficace" d'un arrêt cardiaque par le massage cardiaque en thorax fermé. Le malade avait un thorax en entonnoir où les os se prolongeaient en-dessoús de la partie inférieure du sternum; nous avons l'impression que cela a contribué au traumatisme grave du foie.

A la fin, l'auteur énumère des situations où le médecin devrait traiter l'arrêt cardiaque par compression directe du coeur plutôt que par compression du coeur en thorax fermé.

\section{REFERENCES}

1. Kouwenhoven, W. B.; Jude, J. R.; \& Knickerbocker, G. G. Closed-Chest-Cardiac Massage. J.A.M.A. 173: (1960).

2. Wetherilu, S. H. \& Nrxon, P. G. F. Spontaneous Cessation of Ventricular Fibrillation during External Cardiac Massage. Lancet, 993 (May 12, 1962).

3. Pryon, W. J. Some Studies on Extemal Cardiac Massage. Brit. J. Anaesth. 34: 566 (1962).

4. Redding, J. S. \& Cozine, R. A. Comparison of Open-Chest and Closed-Chest-Cardiac Massages in Dogs. Anaesthesia 22: 280 (1961).

5. Minuck, M. The Management of Cardiac Arrest. Canad. M.A.J. (to be published).

6. Yassman et al. Closed-Chest-Gardiac-Resuscitation in Acute Myocardial Infarction. Am. J. of Cardiol. 7: 731 (1961).

7. Julian, D. G. Treatment of Cardiac Arrest in Acute Myocardial Ischaemia and Infarction. Lancet, 840 (Oct. 14, 1961).

8. Index Medrcus of the National Library of Medicine, March 1962-Octbber 1962.

9. Baringer, J. R.; Salzman, E. W.; Jones, W. A. \& Friedlich, A. L. External Cardiac Massage. New Eng. J. Med. 265: 62 (1961).

10. Clark, D. T. Complications Following Closed-Chest-Cardiac Massage. J.A.M.A. 181: 337 (1962).

11. Purkis, I. E. \& MaHAKIN, R. N. An Unusual Complication of Closed-Chest Cardiac Massage. Canad. Anaesth. Soc. J. 9: 279 (1962).

12. Morgan, R. R. Laceration of the Liver from Closed-Chest-Cardiac Massage. New Eng. J. Med. 265: 82 (1961).

13. Thaler, M. M. \& Krause, V. W. Serious Trauma in Children after External Cardiac Massage. New Eng. J. Med. 267: 500 (1962).

14. Negovskir, V. A. Resuscitation and Artificial Hypothermia, p. 33. Cónsultants Bureau (1962). 